Tem a palavra, para relatar a tese, o professor Bruno de Mendonça Lima.

O SR. BRUNO DE MENDONÇA LIMA - Exmo. Sr. Presidente, Srs. Congressistas, minhas senhoras, meus senhores.

Coube-me a honrosa missão de dar parecer sôbre a tese n. ${ }^{\circ} 30$, de autoria do eminente professor Hernani Estrella.

A contribuição do Professor Estrela, intitula-se "O Código Comercial no Século". Vou ler o relatório e, em seguida, meu parecer à respeito.

$$
\text { (LÊ o Relatório) }
$$

O SR. BRUNO DE MENDONÇA LIMA - Foi o resumo que pude fazer das quase 90 páginas do trabalhos apreciado. Agora vou emitir o meu parecer.

$$
\text { (LE o Parecer) }
$$

O SR. BRUNO DE MENDONÇA LIMA - O parecer foi aprovado com um adendo, proposto pelo nosso ilustre Presidente. Êste adendo consiste em que, na sessão de encerramento do Congresso seja lido êste voto da Comissão, constando, portanto, dos trabalhos de encerramento, a homenagem que a Comissão propõe se preste ao professor Hernani Estrela. (Palmas).

O SR. PRESIDENTE - O trabalho do professor Hernani Estrela não contém conclusões que possam ser motivo de um debate jurídico. Não obstante, como o tema é sugestivo e realmente atinente à cultura jurídica brasileira e argentina, está em discussão, para qualquer observação ou comentário a respeito.

Se não se formula nenhum comentário a respeito, vamos tratar do segundo ponto da Ordem do Dia.

\section{O CÓDIGO COMERCIAL, O REGULAMENTO DE 737 E MAUÁ}

\section{Vicente Russomano}

A efeméride, por todos os títulos gloriosa, que êste Congresso. Jurídico do Rio Grande do Sul evoca, merece, por sem dúvida, uma homenagem condigna, mas, também, pode receber a contribuição modesta e simples de um advogado. Ao lado da crítica cabe a eloqüência, no erudito conceito de Oliveira Martins ao perfilar nas pompas farfalhantes de seu estilo incomum o "Poeta da Raça".

Este augusto conclave de juristas patrícios presta uma homenagem expressiva à magna data rememorada.

Ao lado de estudos proficientes e de teses prenhes de erudição cabe, incontestàvelmente, um singelo trabalho de exaltação, escrito como êste o é, com o coração aberto à admiração de um passado ilustrado e magnífico.

A insigne data, que êste Congresso de Juristas relembra, está aureolada pela profunda, calorosa e suma admiração do nosso civismo e do nosso indestemido patriotismo.

Não há que fugir do sentimentalismo emocionante da data ou seja o primeiro centenário da promulgação do Código do Comércio do Império do Brasil. Falta-nos, reconhecêmo-lo, competência para entrajar êsse trabalho com a observação de uma crítica original, mas, em compensação, sobra-nos entusiasmo, que, no caso, é chama fecunda e é também emoção criadora, para prestar êste nosso culto admirativo aos nobres patrícios que elaboraram êsse notável corpo de leis comerciais, e que tanto enaltece a inteligência daquela nobre e digna gente.

Rendamos, pois, preliminarmente, nosso expressivo e altissonante culto aos que souberam elevar tão soberanamente o nome do Brasil, promulgando um Código de Comércio, cuja centúria aqui comemoramos, sendo êsse nosso culto um elo de ouro, forjado ao calor de nosso entusiasmo, unindo, na vida, o passado ao presente para projação de um futuro, ainda mais alto e mais fecundo, para maio grandeza e glória do BRASIL. 
Este conclave de Cultura Rio-grandense também é rememorativo de uma outra data, que não queremos deixar passar em olvido: relembra o cinqüentenário da fundação da Faculdade de Direito de Pôrto Alegre. Justo é, ontrossim, a evocação, porque tem ela a expressão de um culto profundamente humano aos que deram o primeiro impulso à criação de um centro acadêmico, qué tanto cooperou para a elevação moral da brava gente dos pampas rio-grandenses.

E tão grande e tão soberba tem sido a colheita propiciada por essa vetusta Faculdade, que, se não fôsse o receio de modificar o nosso primeiro propósito, bem poderíamos escrever um simples trabalho, sob a rubrica "A Faculdade de Direito de Pôrto Alegre e c seu Destino Histórico".

Incontestàvelmente a velha e respeitável Faculdade de Direito é um centro de gravitação histórica do nosso amado céspede natal e foi o primeiro núcleo formador dessa invejável cultura acadêmica que o Rio Grande ostenta no talento e inteligência de seus filhos.

Nesta Faculdade tiveram início tôdas as agitações, quer social, quer ideológicas, do tormentoso início do século 19 , tornando o Rio Grande do Sul a atalaia indormida da unidade política do Brasil.

Esta tese está exigindo uma meditação mais detida, mais profunda. Nosso escopo, em relembrando a data, é, apenas, mencionar a atividade incomum da Faculdade de Direito e prestar também nosso culto de saudade aos mestres eminentes André da Rocha, por tantos anos, o seu Diretor e animador, Melchisedech Matusalém Cardoso, Joaquim Ribeiro, Leonardo Macedônia, Joaquim Maurício Cardoso, Rodolfo Simch, e tantos outros, cujos nomes, embora aqui não grafados, merecem, em silêncio, a nossa veneração, respeito e gratidão.

A instalação dos Cursos Jurídicos, no Brasil, no século 19, destaca a nobre orientação dos nossos Estadistas, que bem compreenderam que o Brasil só poderia usufruir sua independência, quando o seu povo pudesse ter a facilidade de adquirir na própria Pátria os conhecimentos do ensino superior.

Houve patrícios convictos da necessidade de ser facilitado êsse assunto e surgiram na Câmara dos Deputados diversos projetos, que não tiveram êxito, pois, também havia outros que se opunham a essas tentativas, porque desejavam manter o Brasil vinculado à $\mathrm{Me}$ trópole Portuguêsa.

Finalmente foi vitorioso o projeto relatado pelo tribuno José Januário da Cunha Barboza, um dos mais operosos artífices da nossa Independência Política, e cujo projeto foi convertido em lei, aos 11 de Agôsto de 1827, tendo sido referendado pelo Visconde de São Leopoldo, que fôra, aliás, o primeiro patrício a alvitrar a idéia da fundação dêsses cursos culturais, no Brasil.

Desmembrou-se dessarte o ensino superior de Portugal e pôde desde então, com as Faculdades de Recife e são Paulo, inaugurar o Brasil uma nova e esplêndida fase cultural, chegando seus benefícios até o Rio Grande do Sul, com a fundação da nossa gloriosa Faculdade de Direito, cujo cinqüentenário também aqui é festejado,

os mais expressivos aplausos de reconhecimento e gratidão. ção de mocos idealistas de seus bancos acadêmicos saiu uma geraviços ao Brasil prestaram inestimáveis seracadêmica ou nos jornais a liberdade e a justiça social na tribuna alta armais e mesmo no Parlamento Brasileiro alta administração do País e se tornaram porta-vozes dessas liberdades públicas, que servem de pedestal à Glória da Pátria.

$$
-\mathrm{O}
$$

O Código Comercial do Império do Brasil é o nítido reflexo das idéias político-liberais da época. Apresenta uma fisionomia própria. Honra um País. Enobrece uma geração. Como o Código Código Criminal também, a legislação criminal dêsse tempo, bem como o Código de Processo Criminal, de 1832 das famosas ordenações protesto do Brasil contra o odioso Livro V das famosas ordenações do Reino, tornou-se notável, como escreve legislação imprimiu à "não só pela sistematização que essa famosa lhante na históri justiça criminal, como carma um período brielaborado por Alves judiária do Brasil. Instituiu o Código Criminal, elaborado por Alves Branco, definitivamente o Hábeas-Corpus, ao

qual já fazia referência o Código Criminal de 1830".

velmente tão olsando as páginas da nossa História Política, lamentàfortemente arraigado nos dias presentes, sentiremos como estava Tendo o Gabinete de 23 sentimento popular o ideal de liberdade. de dezemro de 1841, revogado, pela lei de 3 por êsse motivo a de São Paulo, e nesse mesmo ano duas enaltecedoras revolucões: frente dos reivindica aparece o vulto hercúleo de Padre Feijó, Minasica da liberdade pública do Brasil e , sob o comando do excelso liberal Téfilo ambos ergueram, pelas armas, o protesto liberal Teófilo Ottoni, Códigos, que eram numes untra a revogaça de E se analisarmos do povo Brasileiro. conhecida escola fo naís sob o prisma da própria", que natosófica que "considera a lei dotada de uma fôrça propria", que, naturalmente, se transforma com o decorrer do tempo, intérprete verificar tais transformações, veremos que colhido preceitos ter o Código de Comércio do Império do Brasil trina, foi o que deuencos de liberalismo, e, não específicos da doulargo trecho de tempo. 
isento de idéias, teorias e teses preconcebidas, porque, já conceituava Planiol escrevendo sôbre o Código de Napoleão, "a lei não deve ser feita sòmente para uso de uma geração ou para satisfação intelectual de uma escola".

O Código de Comércio, cujo centenário memoramos, avançou e venceu, porque se afastou, inteligentemente, dêsse clima apaixonado e personalista, e generalizou, não particularizou, exaltou princípios flexíveis, genéricos, e não específicos e pessoais.

São efêmeras as leis redigidas em meio de tormentosos climas políticos, pois defendem êsses princípios particulares, olvidando os interêsses mais gerais.

Vimos que os legisladores contornaram essas dificuldades e elaboraram um Código de Comércio já de per si vencedor.

Essa tendência liberal já fôra revelada pelo Brasil, e que constitui fato culminante da nossa história política, como fatal resultado do patriotismo, que orientava a gente do País.

E a Carta-Régia de 29 de Janeiro de 1808 precedeu, com êsse contôrno de independência, a própria constituição do Brasil-reino, o que se verificou com a Carta Lei de 16 de Dezembro de 1815, muito embora, já o Brasil tivesse sido, anteriormente à essa data, reconhecido reino pelas grandes potências da Europa, como no memorável Congresso de Viena, reunido logo após à derrota de Napoleão, e com o nobre propósito de recompor o mapa da Europa, retalhado pela espada de Napoleão. Nesse conclave rebrilhou o talento político de Mettanich, o "Príncipe do Equilíbrio".

Mas, como acentua o grande Prof. Martins Júnior, na sua valiosa obra "Direito Nacional" qualquer que fôsse, porém, o móvel do Decreto de 28 de Janeiro de 1808, êle ficou sendo, nos arquivos do direito pátrio, a nossa primeira carta de alforria econômica, o título primitivo da nossa emancipação comercial. E quando, em 18 de Junho de 1814 , foi ampliada a providência que êle continha, permitindo-se aos navios de tôdas as nações a livre entrada nos portos brasileiros, franqueando-se também a saída para qualquer destino das embarcações nacionais, afirmou-se a real e futurosa a tendência do Brasil para a sua plena independência econômica-industrial". (obr. cit. pág. 240, edição 1895).

Cada época na história tem uma fisionomia própria.

A do século em que foi elaborado o primeiro Código Comercial do Brasil não podia fugir a influência das idéias liberais do século 18 .

Bosquejando-se, ainda que perfuntòriamente, a fisionomia jurídica dêsse período histórico a que nos estamos referindo, perceberemos a predominância dos institutos e leis liberais e sendo o Brasil o palco de uma profunda revolução político-social.

E Martins Júnior, na obra já acima citada, constata, com profunda erudição: "Podemos pintar em dois traços a atividade legislativa do Brasil de 1808 a 1822, como afirmar a exclusiva propondas polítios institutos do direito público interno e externo: medidas políticas, administrativas, financeiras e diplomáticas".

Daí o acêrto da observação e culto reparo do consagrado Mestre Carvalho de Mendonça (J. X.), dizendo: "O Código é deficientísinsigno na matéria de direito comercial”. Pleiteava, já em 1878, o insigne Mestre Teixeira de Freitas "uma reforma da nossa legislação
comercial".

Essas críticas reforçam o pensamento de que o Código de mércio do Império do Brasil reflete as idéias avançadas da época, consolidando os lídimos princípios liberais do comércio.

Tanto isso ressalta da Consolidação, procedida, que todos os mestres incluso Carvalho Mendonça, criticavam o nosso primeiro e único Código de Comércio como remisso aos reclamos do comércio nômicos, de que legais. Mas, de que legais.

Mas olvidam êsses mestres que êsse Código pôde vencer tão longo decurso de tempo, uma centúria, justamente porque êle reo ideal políticosses mais políticos, do que econômicos, servindo assim - ideal político dessa época.

\section{CÓDIGO COMERCIAL}

O direito comercial, diz Carlos de Carvalho, no seu valioso livro "Dir. Civ. Bras. Recopilado", é apenas um agrupamento ex-
terno".

Desmembrou-se do direito privado para formar uma subdivisão, obedecendo ao desenvolvimento dos fatos jurídicos e das instituições' econômicas que devia reger.

A flexibilidade, a mobilidade, o caráter internacional ou de universalidade das relações comerciais não se acomodavam à lentidão dos movimentos das demais instituições do direito privado.

"Explorando tôdas as relações comerciais do direito privado. variadas funções, transporte, guarda, compra e venda, e estudada as relações de ordem econômicas e sociais, foi o comércio explorado

E êsse fato acrescido com as determinações histórico-políticas possibilitaram a formação de um direito comercial e a sua criação como ramo autônomo da árvore jurídica. 
E sob êsse clima se formou o Código de Comércio Francês, e por uma conhecidíssima lei de imitação, a influência dêsse Código for grande na elaboração dos demais Códigos de Comércio do Ocidente.

A Holanda seguiu-lhe os passos, e depois a Itália, a Espanha e a Grécia, sendo que o da Espanha, de 1829, serviu de modêlo ao de Portugal, e daí, por um por outro dos mencionados Códigos, aparece sua influência no Mundo Novo.

Evidentemente "o direito comercial não pode ser mais o direito de uma classe de pessoaş, mas de uma certa ordem de relações humanas". C. Carvalho.

$$
-\mathrm{O}-
$$

Adamastor Lima, na sua recente obra, elogiada pelo insigne Basílio Magalhães, "Tratado do Direito Comercial", tendo, agora, publicado a "Introdução do direito comercial", ohde estuda agora, publicado a Introduçáo do direito comercial do Brasil, proficientemente a parte historica do direito comercial do Brasil, analisa a influência do mercantilismo e livre-cambismo, depois o protecionismo, até ùltimamente, o coletivismo, corporativismo e intervencionismo.

E no decurso dêsse trabalho afirma, com a competência que the restres brasileiros: "a abertura dos portos do Brasil ao comércio exterior pela Carta Régia de 28 de Janeiro do 1808 FOI O PASSO FIRME PARA NOSSA PROJEÇÄO NO MUNDO ECONOMMICO”.

Já o Mestre Martins Júnior, no seu esquecido livro - que é de lamentar - "História do Direito Nacional" asseverara: "A Carta Régia de 28 de janeiro de 1808 ficou sendo, nos arquivos do direito pátrio, A NOSSA PRIMEIRA CARTA DE ALFORRIA ECOpátrio, A NOSSA PRIMEIRA CATIVO DA NOSSA EMANCIPAC̄O NÔMICA, O Tİ

Qualifica êsse como primeiro título de emancipação, porque o outro, é o fato de que no Brasil "a vida comercial precedeu a civil, afirmando, com erudição: "O Brasil nasceu, pois, sob o signo do afırmaño, com erudínC, e, pela sua posição geográfica. e pelos recursos de que é dotado, HÁ DE CUMPRIR A SUA DESTINAÇÃO HISTÓRICA".

\section{DA HISTÓRIA DA LEGISLAÇÃO COMERCIAL DO BRASIL}

Já vimos acima que o Decreto de 28 de janeiro de 1808, que abriu os Portos do Brasil ao comércio das Nações amigas, assinala uma Nova Época na vida política do nossa País.
Foi, diz Martins Júnior, "o título primitivo da nossa emanr. cipação comercial".

Quem se dispuser a pesquisar as origens do Direito Português, que é a forma direta do Direito Brasileiro, inferirá que êsse Direito de Portugal foi criado sob inspiração do Direito Romano, Germânico e Canônico.

Reflexos das invasões guerreiras da península Ibérica, pois, foi só em 1140, desmembrando-se dessa península, que Portugal adquiriu sua Independência Política, com Afonso Enrique, na batalha de Valdevez e Ourique.

Segundo a lição clara e erudita de Pontes de Miranda, uma das excelsas figuras do nosso mundo jurídico, "a influência do direito romano, foi mais política, do que moral e religiosa, e a do direito germânico, mais de ordem moral, do que política e religiosa e, finalmente, a do direito canônico, mais religiosa, do que moral e política".

Por essa linha de evolução do nosso Direito verificar-se-á que constitui fato culminante da nossa História Política, o Decreto de 28 de janeiro de 1808, assinado por D. João $6^{\circ}{ }^{\circ}$, então Regente de Portugal, devido ao estado de confusão mental de D. Maria I. ${ }^{a}$.

Sabido é que D. João $6 .^{\circ}$ se viu constrangido a procurar refúgio no Brasil, fugindo assim da invasão Napoleônica. Aportando à Bahia assinou o dito Decreto, por conselho de Visconde Cayrú, José da Silva Lisboa, que, trabalhos recentes, o consideram um ins-trumento da política imperialista da Inglaterra.

Mas quaisquer que sejam as críticas, a verdade é que êsse Decreto assinala um grande movimento renovador político-econômico do Brasil.

Estava o mundo sob os clarões das chamas rubras do glorioso movimento de 89 , e, êsse movimento liberal repercutiu fortemente no Mundo Novo.

Elaborado já nos meados dêsse século 19, o Código de Comércio do Império do Brasil, cujo $10^{\circ}$ Centenário está sendo festejado, não pôde fugir ao contágio dessas idéias avançadas, e, sob essa égide, incentivou o comércio exterior, a ponto de causar ciúmes das demais grandes Nações da América do Sul, a Argentina, principalmente, e pôde assim êsse Corpo de Leis avançar pelo futuro a dentro.

A capacidade dos que prepararam o "Código de Comércio", ficou soberanamente engastada nessa obra perene de conquistas liberais do Brasil.

É essa intenção que justifica a presença de quatro comerciantes na organização dêsse Código, o que denuncia o propósito governamental em dotar o País de um Código útil, eficiente e prático.

Já em 1809 o Tribunal da Real Junta de Comércio encarregava Silva Lisboa de organizar o Código de Comércio. 
"O não havia proclamado oficialmente sua Inde. Êste fato merece honppendência e cogitava Carvalho de Mendonça (J. X.).

rosa referência", diz Carvalho de Mendonça não ofereceu material

$O$ trabalho de Silva Lisboa, entretanto, năo ofer iniciados em para a projetada codificação, cujos trabalhos foram 1833, sob a Regência Permanente composta do Brigadeiro Lima e Silva, João Bráulio Muniz e José da Costa Carvalho - (Marquês de Monte Alegre).

E todo êsse largo trecho que vai de 1808 até 1833 podemos E todo esse largo trúp liberais do Brasil.

classificar como os das núpcias liberais do Brasil.

Foi nesse ano de 1833 que Visconde de Sepetiba - Aureliano de Souza e Oliveira Coutinho - nomeou uma comissão de quatro començo ciantes, que foram: José Antonio Liso Midosi, para cooperarem na Westin, cônsul da Suécia, e Guilherm

-elaboração do Código de Comércio.

Coube a presidência da comissão ao espírito liberal a essa obra immente Perei perecível.

É digno de registro êste fato, porque o Conselheiro Clemente Pereira foi notável estadista, presidente do Senado da Câmara do Rio de Janeiro e presidente do Tribunal de Comércio, e como poRio de Janeiro e presidente das conquistas da nossa Independência, lítico estêve na vanguarda das conquistas da e de tôdas as campanhas liberais, bastando assinalaripe Regente lemoutros ilustres patrícios, que representou ao Príncipe Regente lembrando a necessidade da convocação de um Conselho de Procuradores Gerais das Províncias, convocado antes da Independência e que foi a origem da primeira

reunida aos 3 de Maio de 1823.

Vimos assim que ao Visconde Cayrú se junta Clemente Pereira, aquêle instigando d. João $60^{\circ}$ à assinatura do Decreto de 28 de Jaaquele instigando liberais do neiro de 1808, e éste comércio.

Verdade é que, nesse período, aparecem traços inapagáveis da . influéncia da dirasil, analisando a recente conferência de Sir Nevile sociólogo do Brasil, analisando a recente junto ao Govêrno do Brasil, Butler, Embaixador da Gran-Bretanha junto ao Governo do Brasil, acentua, que nessa fase da nossa Historia, não se pode esquecer. ação de Canning, "que favoreceu de forma notavel a Independência do Brasil e é o traço de união entre o Brasil e a Gran-Bretanha no 'século 19".

A comissão nomeada deu cabal desempenho à sua tarefa, apreentando o projeto em 1834 e inspirada sôbre os Códigos de Coéceríodo êsse em que o trámércio da proporções desusadas, exigindo do Brasil medidas acauteladoras contra o imperialismo dos mares, que era a política de John Bull.

Depois dos trâmites regulamentares pelas casas do Legislativo do Brasil, foi o projeto submetido a uma comissão mista de membros da Câmara e do Senado, composta do Marquês de Maricá, Rodrigues de Carvalho, Paula e Souza, Amaral Gurgel e Moura Magalhães, cuja comissão apresentou parecer favorável, aos 11 de Outubro de 1835 .

Houve em seguida um novo esquecimento, sendo, afinal, o Código de Comércio promulgado pela Lei $n .^{\circ} 556$, de 25 de Junho de 1850, para ter execução aos $10^{\circ}$ de Janeiro de 1851 .

Foi êsse o primeiro Código de Comércio original da América, pois, que se os outros países americanos, promulgaram, anteriormente, seus Códigos de Comércio, foram trabalhos copiados ou decalcados nos Códigos da Itália, França e Espanha e sendo que a França iniciara a Codificação das Leis de Comércio, sôbre o reinado de Luiz XIV e em 1801 promulgava o seu famoso Código de Comércio, que serviu de fonte imediata a todos os demais que se seguiram, inclusive para o do Brasil, muito embora seja o primeiro código original da América do Sul.

\section{CÓDIGO COMERCIAL E O REGULAMENTO N. 737}

O Código de Comércio do Império do Brasil mostrou o adiantamento surpreendente do nosso meio jurídico, e como acentua Cândido Mendes "é uma legislação firmada com o cunho brasileiro, revelando, enre outros dotes, no espírito e na redação, o labor e o colorido pátrio", e foi êsse Código a fonte de uma outra lei, que é considerada, por todos os Mestres, como "um dos monumentos mais sólidos da nossa legislação", que é o Regulamento 737 de 25 de Novembro de 1850 .

E tão impressionante é êsse Regulamento, que escreve Carvatho de Mendonça, no seu notabilíssimo trabalho "Direito Comercial Brasileiro", vol. 1. " pág. 50: "Os homens da República, na obra nefasta do esfacêlo da legislação, RECUARAM RESPEITOSAMENTE ANTE ESSA ADMIRÁVEL PEÇA", mas o que a primeira República respeitou, como elogiosa referência aos fundadores da $\mathrm{Re}$ pública, os do Estado Novo esbarrondaram estrepitosamente..

Êsse Regulamento traçou o processo, e completou, com muitos preceitos, o próprio "Código de Comércio".

Esse projeto foi elaborado por uma comissão composta de Clemente Pereira, Nabuco de Araújo (José Tomaz), Carvalho Moreira (Barão de Penedo), Caetano Alberto Soares e BARÃO DE MAUÁ (Irineu Evangelista de Souza). Este Irineu Evangelista de Souza, 
Barão e depois Visconde de Mauá, foi um homem que perseguiu, em vida, um ideal, que nunca o perdeu de vista durante sua vida tormentosa e cujo ideal êle entregou, como seu tributo pessoal, à grandeza moral do Brasil.

Mauá jamais recusou um serviço à Pátria. Nunca temeu a dura realidade, antes enfrentava as angústias com a fortaleza das almas sinceras e nobres.

Encheu um largo período da História do Brasil com seu nome ilustre. Com seu labor incessante engrandeceu o meio comercial e financeiro do Brasil e da América. Com sua operosidade invulgar e seu engenho incomum, contribuiu decisivamente para o futuro do nosso País.

Era um espírito prático. Era um patriota ardoroso. Amou a Brasil. Serviu a Pátria, com desinterêsse e entusiasmo raro. E sôbre êsses alicerces robustos construiu sua grande obra e seu nome brilhou entre os mais aureolados dessa época, que se distinguem pelo valor moral dos ilustres varões dêsse período áureo de nossa vida política social.

Uma série de circunstâncias influíram, por sem dúvida, para formar sua individulidade moral.

A infância the foi avara, pois, aos 9 anos deixara, órfão de pai, a casa, sita no Arroio Grande, neste Estado, sem que tivesse aprendido sequer as primeiras letras. Foi, primeiro, empregado na casa comercial de Antonio José Pereira de Almeida, quarido tinha 12 anos e daí passou a ser empregado de Ricardo Carrúthers, súdito inglês e, tinha, na ocasião, 17 anos de idade. Assim foi iniciada a carreira comercial de um dos mais autorizados e categorizados representantes. das Finanças do Brasil.

E resumiu tôda a sua gloriosa vida no folheto "Exposição aos Credores", que é uma página que emociona até as lágrimas.

Exerceu na Câmara dos Deputados funçôes de larga repercussão tanto no meio político como social e econômico do País.

O Repto de "Silveira Martins" é uma outra página brônzea e na qual esplende tôda a beleza moral de sua egrégia personalidade.

Foi êsse o nome elegido para representar o comércio do Brasil, como já se procedera, anteriormente, na elaboração do Código do Comércio, na fatura do celebrizado Regulamento 737.

Joaquim Nabuco, no formoso livro "Um Estadista do Império", destaca a latuação de Mauá nesse "Regulamento" que êle chama "a mais perfeitamente trabalhada de nossas leis", e, mantida pelo Govêrno Provisório da República, como um reconhecimento expresso do valor mental de seus organizadores.

$\mathrm{Da}$ comissão de juristas, todos de justa fama, nomeados e escolhidos com alto critério, por Euzébio de Queiroz, "só um era estranho ao templo da ciência, um moço, um comerciante de 36 anos, que, no ano seguinte, ganharia, como prêmio, o oficialato da Ordem da Rosa Irineu Evangelista de Souza".

Latino Coelho, ao perfilar Frei Francisco de S. Luiz - um Estadista do Império - escreveu: "Quantos homens têm havido no mundo que só de heróis tiveram um dia as palmas, que lhes ceifou a ocasião, ou de sábios o laurel, que lhes enramou a parcialidade. Grandes na terra e na vida; pequenos nas cinzas e no túmulo".

Mauá, se foi grande na vida e na terra, ainda maior se tornou nas cinzas e no túmulo.

As palmas que lhe ornaram a fronte honesta em vida foram conquistadas pelo seu labor honrado e sua inteligência rara e não foram tecidas pela parcialidade, e, por isso, entre as comemorações do $10^{\circ}$ centenário da promulgação dêsse Código, reverdecem êsós do $10^{\circ}$ com o mesmo viço e a mesma luz esplêndida e fecunda, aureolando essa nossa sincera manifestação de cívica gratidão, cercando seu
nome de prestígio enobrecedor.

A espada constrói, destruindo; mas o ideal, é oxigênio vital, é essência criadora, é fôrça altiva e podemos, entre as homenagens mais votivas dêste Congresso, arvorar o exemplo de Mauá, como troféu dos princípios de democracia, liberdade e justiça do Brasil.

E pelo conjunto dêsse todo, pelas conquistas políticas e sociais dessa centúria, pela seqüência de lições magníficas que êsse longo curso de cem anos, 1850 a 1950, desperta na consciência do povo Brasileiro cem anos, 1850 a 1950, desperta na consciência do povo Brasileiro, esta Comemoração toma os luminosos contornos de uma invulgar festa cívica, na qual, sobranceiramente, só erguemos, com desassombro democrático, a bandeira doutrinária, que essa geração de patriotas nos legou e que nós não deixaremos rolar essa geração quecimento e muito menos se macular nas brumas da ingratidão

\section{RELATÓRIO E PARECER}

\section{Relator: PAULO BARBOSA LESSA}

1 - O professor Vicente Russomano, que vem de há muito ilustrando a cátedra que professa na Faculdade de Direito de Pelotas, traz à consideração do congresso uma preciosa monografia, em que ressalta, em ligeiros e seguros traços, as linhas mestras do Código do Comércio do Brasil, do Regulamento 737, de 1850.

2 - Para o Prof. pelotense, o segrêdo da vitalidade do Código do Comércio, que ora completa o seu centenário de vigência, está na perfeita adequação a dois dados de excepcional importância: o primeiro está no reconhecimento do liberalismo então vitorioso sem 
contraste, o segundo no reconhecimento das necessidades econômicas da nação, até mesmo antes da sua independência.

Com tôda a justeza, é sustentado ser o Código do Comércio de 1850 uma expressão do liberalismo vitorioso no século dezenove. Essa adequação ao fenômeno político é, deveras, irrecusável, nela residindo, sem dúvida, uma das razões eminentes da longevidade do nosso diploma legal.

O outro dado, que é pelo autor pôsto em destaque, bem evidencia a segurança com que a matéria é tratada. Na realidade, como em frase feliz foi ressaltado pelo ctedrático desta Escola, o "Código de comércio constituiu contínua e persistente aspiração de classe". Como salienta o autor, seu germe estava na lei de 1808 , que abriu os portos do Brasil às nações amigas. Dado o primeiro passo, conseguido o primeiro triunfo, a classe dos comerciantes, cada vez mais pujante, lutou tenazmente pelo coroamento de seus desejos. O Código de 1850 representa, sem dúvida, o fecho de seu esfôrço. Não prometido pela constituição do império, o Código foi dos que primeiro surgiu, explicado pela tenacidade e pelo poderio da classe dos mercadores no Brasil.

3 - Dá em rápidos traços o depoimento de nossa doutrina, aliás depoimento unânime, sôbre a excelência do Regulamento 737, completo Código do Processo Civil, e que, travestido nos Códigos Estaduais, regeu o Processo Civil até o recente Código, de 1938.

4 - Por último, ressalta o autor a personalidade inolvidável do co-estaduano Irineu Evangelista de Souza, Barão e Visconde de Mauá. Representou êle a classe dos comerciantes na elaboração do Regulamento 737. Um dos mais operosos membros dessa classe, a quem o Brasil deve tanto, Mauá representou na comissão o espírito dêsses mercadores que exigiam a lei disciplinadora da atividade mercantil, como uma necessidade inadiável para o progresso da nação.

5 - Somos de parecer que o plenário aceite a tese, ressaltados o brilho e a segurança da dissertação.

\section{CENTENARIO DEL CODIGO DE COMERCIO BRASILEÑO}

\section{Sagunto P. Pérez Fontana*}

Professor de Direito Comercial na Faculdade de Direito de Montevideo.

Se cumple este año el centenario del Código de Comercio del Brasil, acontecimiento que debe ser celebrado no solamente por los juristas de ese país, sino también por los de los demás países, especialmente por los del nuestro y la Argentina, dada la preponderante influencia que dicho cuerpo de leyes tuvo en la preparación de nuestros respectivos Códigos de Comercio.

Corresponde a los autores brasileños hacer la historia del Código de Comercio de su país; historia que por otra parte ocupa lugar preponderante en los grandes tratados de Derecho Comercial como son de J. X. Carvalho de Mendonça, Waldemar Martins Ferreira y Alfredo Russel, para no citar sino los que nos son mas conocidos.

Sin perjuicio de ello y para rendir cumplido homenaje a quienes contribuyeron a la realización de esa obra que fué, en su tiempo, uno de los Códigos mas adelantados del mundo, haremos una breve y por lo tanto incompleta reseña del proceso de su preparación.

En primer término, debe mencionarse el nombre de José da Silva Lisboa, Vizconde de Cairu, reconocido como el primero de los comercialistas no solamente del Brasil sino de los que escribieron en lengua portuguesa, como lo destacó el eminente autor del Código de Comercio Portugués, Ferreira Borges, cuando afirmaba que sus obras "fueron código mercantil para Portugal hasta la publicación del Código de Comercio portugués”. $\left(^{1}\right)$.

José da Silva Lisboa fué encargado el año 1809 de la redacción de un Código de Comercio, obra a la que dió principio pero no pudo terminar por haberle sido confiada la tarea de escribir la historia del Brasil hasta la declaración de la Independencia. Su nombre no figuró entre los integrantes de la Comisión nombrada el año 1832 para redactar el Proyecto de Código. No nos corresponde a nosotros entrar en detalles del porqué de esa postergación, episodio debidàmente aclarado en su tiempo por los comentaristas brasileños. 